\title{
EŞİK DEĞERİNIN
}

\section{HİSSE SENEDİ FIYYT}

\section{TAHMIN PERFORMANSINA}

\author{
Hacettepe Üniversitesi \\ iktisadi ve Idari Bilimler \\ Fakültesi Dergisi, \\ Cilt 35, Sayı 4, 2017, \\ s. $97-114$
}

\section{ETKISİNIN İNCELENMESI}

\section{Mehmet ÖZÇALICI}

Yrd.Doç.Dr., Kilis 7 Aralık Üniversitesi İktisadi ve İdari Bilimler Fakültesi

Uluslararası Ticaret ve Lojistik Bölümü mozcalici@kilis.edu.tr z: Yapay sinir ağları hisse senedi fiyat tahmininde başarı ile uygulanmaktadır. Eşik değerleri yapay sinir ağlarının performansinı etkileyebilecek önemli bir unsurdur. Bununla beraber yapay sinir ağları modelinde yer alan eşik değerinin tahmin performansı üzerindeki etkisinin incelendiği bir çalışmaya literatürde rastlanmamıştır. Bu çalışmanın amacı eşik değerinin hisse senedi fiyat tahmin performansı üzerindeki etkisini incelemektir. Bu amaçla, BIST100 endeksinde listelenen 100 adet hisse senedine ilişkin 1 Ocak 2014 ve 30 Haziran 2015 tarihleri arasındaki tarihi fiyat ve işlem hacmi bilgileri kullanılmıştır. $\mathrm{Bu}$ verilerden yola çıkmak suretiyle 201 adet teknik gösterge hesaplanmıştır. Yapay sinir ağlarındaki aktivasyon fonksiyonu çeşidi, ara katmanda yer alması gereken nöron sayısı ve değişken seçimi, popülasyon tabanlı meta-sezgisel bir yöntem olan Harmoni Arama algoritması ile optimize edilmiştir. Performans ölçüsü olarak RMSE ve doğru tahmin oranı değerleri kullanılmıştır. Sonuçta eşik değerinin yer aldığı modeller ile eşik değerinin yer almadığı modeller arasında istatistiksel açıdan anlamlı bir performans farklılığı tespit edilememiştir. Bununla beraber eşik değerinin yer almadığı modellerin eğitiminin daha kısa sürede tamamlandığı belirlenmiştir.

Anahtar Sözcükler: Yapay sinir ăglarl, hisse senedi fiyat tahmini, harmoni arama, eşik değeri. 



\section{EXAMINING THE EFFECT OF BIAS ON STOCK PRICE PREDICTION PERFORMANCE \\ OF BIAS ON STOCK PRICE}

Mehmet ÖZÇALICI

Assist.Prof.Dr., Kilis 7 December

University

Faculty of Economics and Administrative

Sciences

Department of International Trade

mozcalici@kilis.edu.tr

\author{
Hacettepe University \\ Journal of Economics \\ and Administrative \\ Sciences \\ Vol. 35, Issue 4, 2017, \\ pp. 97-114
}

A

bstract: Artificial Neural Network models are successfully applied in the field of stock price predicting. Bias values are important factor that can affect the performance of neural networks. Although its importance, the effect of bias on stock price forecasting has not been investigated in literature. The purpose of this study is to examine the effect of bias on stock price predicting performance. For this purpose, historical price and volume information of stocks listed in BIST100 Index is used. By means of these data, 201 technical indicators are calculated. Activation function type in forecasting model and number of neurons in the hidden layer and variable selection are optimized with the Harmony Search Algorithm, a population-based meta-heuristic optimization method. RMSE and hit rate measurements are used as performance indicators. As a result, no statistically significant performance difference was found between biased and un-biased neural network models. However, it has been determined that the training of the models for un-biased models has been completed in a shorter time.

Keywords: Artificial neural networks, stock price predicting, harmony search, bias value. 


\section{GíRIŞ}

Finansal zaman serileri tahmini yatırımcılar, fon yöneticileri ve finansal analistler için önemli bir finansal problemdir ve günümüzde araştırmacıların ilgisini çekmektedir. Genel olarak hisse senedi piyasalarının karmaşık ve dinamik olması tahmin başarısını düşürmektedir. Bu olumsuz durumun etkisini en aza indirgemek için özellikle son zamanlarda araştırmacılar farklı yöntemler geliştirmektedirler.

Hisse senedi fiyat tahmin edilebilirliği Etkin Piyasalar Hipotezi (EPH) ile yakından ilgilidir. EPH'ne göre cari fiyatlar var olan bütün bilgileri içermektedir. Başka bir ifade ile yeni bir bilgi ortaya çıktığında, bu bilgi alıcı ve satıcılar tarafından anında hisse senedi fiyatlarına yansıyacaktır (Fama, 1965). EPH'ne göre hisse senedi fiyatları geçmiş fiyat bilgilerini temel almak suretiyle tahmin edilemez. Bunun nedeni hisse senedi fiyatlarının rassal hareket etmesidir. Buna karşılık hisse senedi fiyat tahmini konusunda destek vektör makineleri (Kara vd., 2011; Yakut vd., 2014), ANFIS (Atsalakis, Valavanis, 2009a; Mahmud, Meesad, 2015) ve yapay sinir ağları (Adhikari, Agrawal, 2014; Hsu, 2013; Kara vd., 2011; Yakut vd., 2014) başarılı bir şekilde kullanılmaktadır. Bu çalışmalardan elde edilen sonuçlar EPH'nin geçerli olmadığına işaret edecek düzeyde başarılı tahmin sonuçları raporlamaktadırlar. Son zamanlarda yayınlanan bir çalışmada (Atsalakis $v d ., 2015$ ) ise finansal kriz zamanlarında bile hisse senedi fiyatlarının başarıyla tahmin edilebildiği sonucu ortaya çıkmıştır.

Hisse senedi fiyat tahmininde kullanılan yapay sinir ağları (YSA) modellerinde nöronlarda eşik (bias) değerleri yer almaktadır. Eşik değeri, sabit bir sayıdır ve nöronal ağırlıklar gibi değerleri eğitim sürecinde değişikliğe uğramaktadır (Hagan vd., 1996: 22). Eşik değerleri modele eklenebilir veya eklenmeyebilir. Literatürde, eşik değerlerinin yer almadığı YSA modeli ile birlikte hisse senedi fiyat tahmini gerçekleştiren bir çalışmaya rastlanmamıştır. Bu çalışmanın amacı, eşik değerlerinin yer aldığı ve yer almadı̆̆ı yapay sinir ağları modelleri ile birlikte hisse senedi fiyat tahmini gerçekleştirmek ve modellerin tahmin performanslarını karşılaştırmaktır. Bu amaçla BIST100 Endeksinde listelenen 100 adet hisse senedinin kapanış fiyatı, eşikli ve eşiksiz yapay sinir ağları modelleri ile tahmin edilmiş ve sonuçların istatistiksel açıdan farklılık sergileyip sergilemediği parametrik olmayan Mann Whitney testi ile test edilmiştir.

Çalışma beş bölümden oluşmaktadır. Bu giriş bölümünden sonra ikinci bölümde literatürde konu ile ilgili yapılmış çalışmalar özetlenmiştir. Üçüncü bölümde çalışmada kullanılan yöntem olan yapay sinir ağlarının temel özelliklerine değinilmiştir. Dördüncü bölümde ise çalışmada kullanılan veri setine, parametreleri belirleyen optimizasyon modeline ve analiz sonuçlarına yer verilmiştir. Beşinci bölümde ise sonuç, tartışma ve sonraki çalışmalar için önerilerden oluşmaktadır. 


\section{LITERATÜR TARAMASI}

Hisse senedi fiyatını tahmin eden birçok çalışma mevcuttur. Borsa İstanbul'da işlem gören hisse senetlerinin fiyatını yapay sinir ağları yöntemini kullanmak suretiyle tahmin eden çalışmaları yayınlandıkları yılları göz önünde bulundurmak suretiyle şu şekilde özetlemek mümkündür. Özdemir (2015) çalışmasında Borsa Istanbul 100 endeksini tahmin etmek için yapay sinir ağı tabanlı bulanık zaman serisi öngörü yöntemini kullanmıştır. Çalışmalarında erişilen sonuçları, parçacık sürü optimizasyonu ile elde edilen sonuçlar ile karşılaştırmıştır. Özçalıcı (2015) çalışmasında BIST30 endeksinde yer alan hisse senetlerinin kapanış fiyatını yapay sinir ağları ile tahmin etmiştir. Çalışmada değişken seçimi ve parametre seçimi meta-sezgisel bir yöntem olan genetik algoritma ile optimize edilmiştir. Çalışma sonuçları, optimize edilmeyen alternatif bir modelin tahmin sonuçları ile karşılaştırılmıştır. Çalışma sonunda önerilen modelin hem istatistiksel hem de finansal açıdan, alternatif modele göre daha iyi sonuçlar ortaya çıkardığı raporlanmıştır. Sarıkaya (2014) ise çalışmasında yapay sinir ağlarını BIST Ulusal 100 endeksini tahmin etmekte kullanmıştır. Yazar, çalışmasında yapay sinir ağları ile kübik regresyon modelinin BIST Ulusal 100 endeksini tahmin etmekteki başarısını karşılaştırmış ve sonuçta yapay sinir ağları modelinin daha iyi performans sergilediğini raporlamıştır. Yakut $v d$. (2014) çalışmalarında BIST endeksini yapay sinir ağları ve destek vektör makineleri ile tahmin etmişlerdir. Çalışmalarında girdi değişkenleri olarak önceki günlere ait endeks değeri, ABD dolar kuru, önceki günlere ait faiz oranı, haftanın günlerini belirten kukla değişkenleri ve diğer borsaların değerlerini kullanmışlardır. Çalışma sonunda Yapay Sinir Ağları yönteminin Destek Vektör Makineleri yöntemine göre daha iyi sonuç verdiğini raporlamışlardır. Aygören $v d$. (2012) BIST 100 (makalenin yayınlandığı günlerde IMKB 100) Endeksinin değerini yapay sinir ağları ve nümerik arama modelleri ile tahmin etmişlerdir. Girdi değişkenleri olarak altın fiyatları, faiz oranı, bankalar arası çift taraflı işlem miktarı ve ABD dolar kuru kullanılmıştır. Çalışmaları sonunda yapay sinir ağlarının kullandıkları alternatif modellere göre daha iyi sonuç verdiğini raporlamaktadırlar. Burada özetlenen çalışmalardan da anlaşılabildiği gibi YSA modeli ile diğer modellerin performansı karşılaştırıldığında, YSA modelinin daha iyi performans sergilediği ortaya çıkmaktadır.

Yukarıda incelenen çalışmalarda, eşik değerinin performans üzerindeki etkisinden bahsedilmemektedir. Buna karşın yapay sinir ağlarındaki eşik değerinin tahmin performansı üzerindeki etkisi farklı alanlarda test edilmiştir. Örneğin, (Wu, Rangayyan, 2007) çalışmalarında eşiksiz doğrusal yapay sinir ağlarını ECG sinyallerinin analizinde kullanmışlar ve eşiksiz yapay sinir ağları modelinin incelenen modeller arasında en yüksek başarıyı gösterdiğini raporlamışlardır. (Yang, Wu, 2007) ise çalışmalarında eşik değerinin bulanık yapay sinir ağları için önemini araştırmışlar ve eşik değerinin vazgeçilemez bir unsur olduğu sonucuna ulaşmışlardır. 


\section{YÖNTEM}

Çalışmada Yapay Sinir Ağları (YSA), tahmin yöntemi olarak kullanılmıştır. Tek katmanlı yapay sinir ağları (YSA) modeli Şekil 1'de yer almaktadır. Modelde her bir $p$ girdisi, ara katmandaki her bir nörona $w$ ağırlığı ile bağlanmıştır. Ara katmanda her bir nöronda aktivasyon fonksiyonu, eşik değeri $(b)$ ve çıktı değeri $(a)$ bulunmaktadır. Eşik değerleri ve ağırlıklar eğitim algoritması tarafından belirlenmektedir.

Yapay sinir ağları modelleri eşik değerli veya eşik değersiz kurgulanabilir. Eşik değerleri modele ek bir değişken eklemektedir. Bu durumda eşikli modellerin daha güçlü olduğunu söylemek mümkündür (Hagan $v d .$, 1996).

Şekil 1'in (ii) bölümünde eşiksiz yapay sinir ağları modeli görülmektedir. Bu modelde eşik değerleri yer almamaktadır. Dolayısıyla bir nöronun çıktısı $a=f(W p)$ ile hesaplanmaktadır.

\section{Şekil 1. Tek Katmanıı Eşikli (i) ve Eşiksiz (ii) Yapay Sinir Ağları Modeli}

(i)
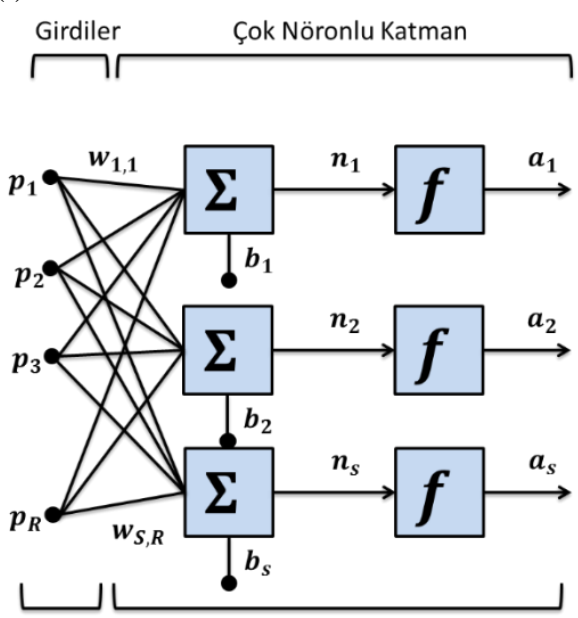

$\boldsymbol{a}=\boldsymbol{f}(\mathbf{W p}+\boldsymbol{b})$ (ii)
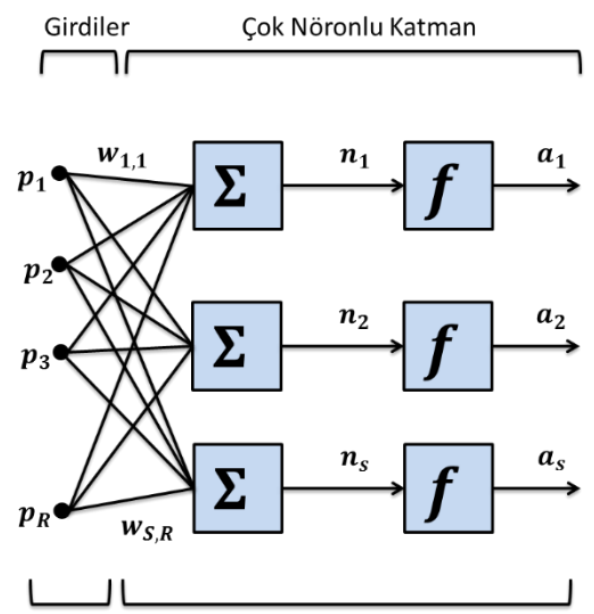

$\boldsymbol{a}=\boldsymbol{f}(\mathbf{W p})$

Çalışmada, yapay sinir ağlarını eğitmek için literatürde sıklıkla ve başarıyla kullanılan Levenberg-Marquardt (LM) eğitim algoritması kullanılmıştır (Atsalakis, Valavanis, 2009b). LM algoritması, yeni ağırlık ve eşik değerlerini, öğrenme parametresi $(\mu)$ değerini kullanmak suretiyle hesaplamaktadır. Öğrenme parametresi olan $\mu$ değeri, eğitim süreci boyunca artmakta veya azalmaktadır. Söz konusu $\mu$ değeri büyük değerler aldığında algoritma speepest descent algoritması gibi davranmaktadır. 
Buna karşılık $\mu$ değeri sıfır değerini alacak kadar küçüldüğünde algoritma, GaussNewton algoritması gibi davranmaktadır (Asadi vd., 2012).

Yapay sinir ağları güçlü bir problem çözme aracıdır. Fakat çok fazla sayıda parametrenin kontrol edilmesi ve modelin eğitim setine aşırı uyum göstermesi gibi olumsuz tarafları mevcuttur (Dai vd., 2012).

\section{ANALIZ}

$\mathrm{Bu}$ bölümde sırasıyla veri seti tanıtılacak, performans göstergelerine yer verilecek ve analiz sonuçları sunulacaktır. Çalışmada analiz yöntemi olarak yapay sinir ağları kullanılmaktadır. $\mathrm{Bu}$ yönteme ilişkin kullanılan parametreler Tablo 1'de listelenmiştir.

Tablo 1. Çalışmada Kullanılan YSA Modeline İlişkin Parametreler

\begin{tabular}{ll}
\hline Parametre & Değerler \\
\hline Girdi katmandaki nöron sayısı & $5,10,15$ ve 20 \\
Gizli katman sayısı & 1 \\
Gizli katman transfer fonksiyonu & Harmoni Arama ile optimize edilmiştir \\
Çıktı katmanı transfer fonksiyonu & Doğrusal çıtı fonksiyonu (purelinear) (y = x) \\
Gizli katmandaki nöron sayısı & Harmoni arama ile optimize edilmiştir \\
Eğitim fonksiyonu & Levenberg-Marquardt Eğitim Algoritması \\
Network Çeşidi & İleri Beslemeli Yapay Sinir Ağı \\
Epoch sayısı & 1000 \\
Minimum grad & $1 \mathrm{e}-7$ \\
$\mu$ & $1 \mathrm{e}-3$ \\
$\mu$ azalış oranı & 0.1 \\
$\mu$ artış oranı & 10 \\
$\mu$ maximum değer & $1 \mathrm{e} 10$ \\
\hline
\end{tabular}

\subsection{Veri Seti}

Çalışmada BIST100 endeksinde listelenen 100 adet hisse senedinin 1 Ocak 2014 tarihi ile 30 Haziran 2015 tarihleri arasındaki tarihi fiyat ve hacim bilgileri kullanılmıştır. Bu aralığın seçilmesinin nedeni mümkün olduğunca güncel bir veri seti kullanmaktır. Söz konusu veriler, Borsa Istanbul'un Datastore bölümünden elde edilmiştir. BIST100 endeksindeki senetler, piyasa değeri ve fiili dolaşımdaki pay oranları dikkate alınmak suretiyle seçilmektedir. Bu nedenle çalışmada 2015 in ilk çeyreğindeki BIST100 Endeksinde listelenen senetler kullanılmıştır. 
Çalışmada kullanılan veri seti, eğitim ve test olmak üzere iki bölüme ayrılmıştır. Eğitim seti, eşikli ve eşiksiz modellerin eğitiminde kullanılmıştır. Test veri seti ise modelin test performansını ölçmek için kullanılmıştır. Başka bir ifade ile test seti eğitim süreci boyunca hiç kullanılmamış, eğitim süreci sonunda ise modelin performansını ölçmek için kullanılmıştır. Eğitim seti, 1 Ocak 2014'in birinci seansı ile 18 Mayıs 2015'in ikinci seans arasındaki toplam 600 seans1 içermektedir. Test seti, 20 Mayıs 2015'in birinci seans1 ile 30 Haziran 2015 'in ikinci seans1 arasındaki 60 seans1 içermektedir.

\subsection{Tahmin Modeli}

Hisse senedi fiyat tahmin çalışmalarında temel göstergelerden veya teknik göstergelerden yararlanılmaktadır. Temel göstergeler firmaların mali tablolarından elde edilen finansal oranlar, diğer ülkelerin borsa değerleri, işsizlik oranları, enflasyon veya faiz oranı gibi göstergelerden oluşmaktadır (Atsalakis, Valavanis, 2009a). Buna karşın teknik analizde hisse senedinin geçmiş fiyat ve hacim bilgileri kullanmak suretiyle hesaplanan teknik göstergeler kullanılmaktadır (Kaufman, 1998). Bir yıldan uzun süreli tahmin gerçekleştirilecekse temel göstergelerin kullanılması, bir yıldan kısa süreli tahminlerde ise teknik göstergelerin kullanılması önerilmektedir (Atsalakis, Valavanis, 2009a). Bu çalışmada kısa vadeli tahmin gerçekleştirileceğinden girdi setinde teknik göstergelerin yer alması uygun olacaktır. Çalışmada bir araya getirilen teknik göstergeler Tablo 2'de sırasıyla listelenmiştir. Çıktı değeri ise bir gün sonraki kapanış fiyatıdır.

Literatürde, hisse senedi fiyat tahmininde kullanılabilecek fazla sayıda teknik göstergenin mevcut olduğu görülmektedir (Achelis, 2001). Bu teknik göstergelerden hangisinin ne zaman kullanılacağına ilişkin hâlihazırda bir yöntem mevcut değildir. Birçok teknik gösterge içerisinden en uygun olanın seçilmesi için literatürde farklı yöntemler önerilmiş̧ir. Bu yöntemlerden biri meta-sezgisel optimizasyon yöntemi olan genetik algoritma ile özellik seçimidir (Yu vd., 2005; Zhai vd., 2010; Özçalıcı, 2015). Diğer meta-sezgisel algoritmalar da özellik seçimi için kullanılabilir. Harmoni arama algoritması meta-sezgisel optimizasyon yöntemlerinden biridir (Yang, 2009). Harmoni arama algoritmasının avantajlarını şu şekilde sıralamak mümkündür; popülasyon tabanlı bir arama uygulamaktadır, uygulanması kolaydır, parametrelere karşı daha az duyarlıdır başka bir ifade ile kaliteli sonuçlar elde etmek için parametrelere ince ayar yapılmasına gerek yoktur (Yang, 2009). Bu avantajlarını göz önüne almak suretiyle Harmoni Arama (Harmony Search) algoritması özellik seçimi ve yapay sinir ağlarındaki parametrelerin optimizasyonu için kullanılmıştır. 
Tablo 2. Girdi Setinde Bulunan Teknik Göstergeler ve Endeksleri

\begin{tabular}{|c|c|c|c|}
\hline Indeks & Gösterge Ad1 & Indeks & Gösterge Ad1 \\
\hline 1 & Toplama Birikim Salınımı & 26 & En yüksek yüksek fiyat \\
\hline 2 & Chaikin Salınımı & 27 & En düşük düşük fiyat \\
\hline 3 & Kapınış Fiyatı MACD & 28 & Medyan fiyat \\
\hline 4 & $\begin{array}{l}\text { 3'ün } 9 \text { günlük üssel hareketli } \\
\text { ortalaması }\end{array}$ & 29 & Denge işlem hacmi \\
\hline 5 & Açılış fiyatı ivme & 30 & Fiyat Değişim ortanı \\
\hline 6 & Kapanış fiyatı ivme & 31 & Fiyat Hacmi Trendi \\
\hline 7 & En düşük fiyat ivme & 32 & Tipik fiyat \\
\hline 8 & Kapanış fiyatı ivme & 33 & Hacmi Değişim Oranı \\
\hline 9 & Açılış fiyatı momentum & 34 & Ağırlıklandırılmış kapanış fiyatı \\
\hline 10 & En yüksek fiyat momentum & 35 & William toplama birikim çizgisi \\
\hline 11 & En düşük fiyat momentum & $36-55$ & $\begin{array}{l}\text { Bir gün önceki } \sim \text { yirmi gün önceki } \\
\text { kapanış fiyatı }\end{array}$ \\
\hline 12 & Kapanış fiyatı momentum & $56-75$ & $\begin{array}{l}\text { Bir gün önceki } \sim \text { yirmi gün önceki en } \\
\text { yüksek fiyat }\end{array}$ \\
\hline 13 & Chaikin Dalgalanma & $76-95$ & $\begin{array}{l}\text { Bir gün önceki yirmi gün önceki en } \\
\text { düşük fiyat }\end{array}$ \\
\hline 14 & Hizlı Stokhastic \%K & $\begin{array}{l}96- \\
115\end{array}$ & $\begin{array}{l}\text { Bir gün önceki } \sim \text { yirmi gün önceki } \\
\text { açıllış fiyatı }\end{array}$ \\
\hline 15 & Hizlı Stokhastic \%D & $\begin{array}{l}116- \\
135\end{array}$ & $\begin{array}{l}\text { Bir gün önceki } \sim \text { yirmi gün önceki } \\
\text { işlem hacmi }\end{array}$ \\
\hline 16 & Yavaşlatılmış Stokhastik \%K & $\begin{array}{l}136- \\
155\end{array}$ & $\begin{array}{l}\text { Kapanış fiyatının bir günlük } \sim \text { yirmi } \\
\text { günlük basit hareketli ortalaması }\end{array}$ \\
\hline 17 & Yavaşlatılmış Stokhastik \%D & $\begin{array}{l}156- \\
175\end{array}$ & $\begin{array}{l}\text { Kapanış fiyatının bir günlük } \sim \text { yirmi } \\
\text { günlük üssel hareketli ortalaması }\end{array}$ \\
\hline 18 & William \%R değeri & $\begin{array}{l}176- \\
195\end{array}$ & $\begin{array}{l}\text { Kapanış fiyatının bir günlük } \sim \text { yirmi } \\
\text { günlük üçgensel hareketli ortalaması }\end{array}$ \\
\hline 19 & Negatif hacim indeksi & 196 & Hareket kolaylığı değeri \\
\hline 20 & Pozitif hacim indeksi & 197 & Trendden arındırılmış fiyat salınımı \\
\hline 21 & Göreli güç indeksi & 198 & Kitle indeksi \\
\hline 22 & Toplanma-Birikim Çizgisi & 199 & Para akış indeksi \\
\hline 23 & Bollinger orta band & 200 & Trix \\
\hline 24 & Bollinger üst band & 201 & Commodity Channnel Index \\
\hline 25 & Bollinger alt band & & \\
\hline
\end{tabular}

Yapay sinir ağları ile gerçekleştirilecek tipik bir tahmin çalışmasında, özellik seçiminin yanı sıra gizli katman sayısı, gizli katman(lar)daki nöron sayısı ve aktivasyon fonksiyonuna da karar verilmesi gerekmektedir (Palit, Popovic, 2005:106). Bu parametreleri optimize edecek halihazırda bir yöntem mevcut değildir. Bu nedenle bu 
parametreleri optimize etmek için de Harmoni Arama Algoritmasından faydalanılmıştır. Kaç adet değişkenin seçilmesini gerektiren bir yöntem mevcut değildir. Bu nedenle 5 , 10,15 ve 20 adet değişken seçildiğinde sonuçların ne olacağı incelenmiştir.

Çalışmada ilk olarak optimize edilecek değerlerin yer aldığı harmoni tasarlanmıştır. Harmonide ilk değer aktivasyon fonksiyonu çeşidini içermektedir. İkinci değer ise ara katmanda yer alması gereken nöron sayısını içermektedir. Geri kalan harmoniler ise değişken indekslerini temsil etmektedir. Çalışmada kullanılan harmoni arama algoritmasına ilişkin kullanılan parametreler ise şu şekildedir: Harmoni belleği kapasitesi 250, harmoni belleğini dikkate alma oranı (harmony memory consideration rate) 0.95 , ton ayarlama oran (pitch adjustment rate) 0.7 , maksimum iterasyon sayıs 200.

Eğitim setindeki 600 adet seans, sıralı iki adet 300 er seanslık alt gruplara ayrılmıştır. Her gruptaki ilk 240 adet seans, eğitim için geri kalan altmış adet seans ise test amacıyla kullanılmıştır. Her iki gruptaki ortalama hata ise harmoni arama algoritmasının uygunluk değeri olarak kullanılmıştır. Bu şekilde eğitim setinin alt gruplara ayrılması aşırı uyum (overfitting) problemini engellemek içindir. Çalışmada önerilen optimizasyon tekniğinin benzeri(Özçalıcı, 2015) çalışmasında da detaylı bir şekilde anlatılmıştır.

Harmoni arama algoritmasında kullanılan harmonilerden ilki aktivasyon çeşididir. 1 ile 10 arası değerler almaktadır ve aktivasyon fonksiyonu çeşitleri Tablo 3 'deki gibidir. MATLAB yazılımında var olan bütün uygun aktivasyon fonksiyonlarına çalışmada yer verilmiştir. Harmoni arama algoritması bu aktivasyon fonksiyonlarından tahmin için en uygun olan aktivasyon fonksiyonunu uygunluk değerini dikkate almak suretiyle seçilmiştir. Üçüncü sırada yer alan hard limit fonksiyonu sınıflandırma problemleri için uygun bir aktivasyon fonksiyonudur. Buna karşın bu çalışmadaki gibi nokta fiyat tahmini gerçekleştiren regresyon tipi çalışmalarda kullanılması uygun olmayacaktır. Ancak yine de bu aktivasyon fonksiyonu listede yer almaktadır. İkinci harmoni ise ara katmandaki nöron sayısını içermektedir. Alt sınır olarak 1 ve üst sınır 30 olarak belirlenmiştir. Daha fazla sayıda nöron kullanmak analizde kullanılan bilgisayarın cevap verme süresini uzatmaktadır. Bu nedenle üst sınır olarak 30 adet nöron belirlenmiştir. 
Tablo 3. Aktivasyon Fonksiyonu İsimleri

\begin{tabular}{ll}
\hline Indeks & Aktivasyon fonksiyonu adı \\
\hline 1 & Tanjant Sigmod \\
2 & Elliot Sigmoid \\
3 & Hard limit \\
4 & Logaritmik Sigmoid \\
5 & Radyal Bazlı \\
6 & Saf Doğrusal \\
7 & Normalleştirilmiş Radyal Bazlı \\
8 & Soft Max \\
9 & Üçgensel Bazlı \\
10 & Net-inverse \\
\hline
\end{tabular}

Çalışmada, analizler gerçekleştirilmeden önce veriler, standartlaştırma işlemine tabi tutulmuştur. Standartlaştırma işlemi ile birlikte farklı ölçeklere sahip değişkenlerin analizde baskın hale gelmesi önlenmiştir. Verileri normalleştirmek için kullanılan standartlaştırma formülü aşağıdaki gibidir;

$$
X_{\text {yeni }}=\frac{X_{e s k i}-X_{\min }}{X_{\max }-x_{\min }}
$$

formülde, $X_{\text {eski }}$ normalleştirmeden önceki değeri, $x_{\text {min }}$, değişkenin en küçük değerini ve $x_{\max }$ değişkenin en yüksek değerini temsil etmektedir. Normalleştirme işlemi sonucunda yeni değerler $[0,1]$ aralığında dağılmaktadır.

\subsection{Performans Göstergesi}

Çalışmada kullanılan performans göstergelerinden bir tanesi Ortalama Karesel Hataların Karesi (Root Mean Squared Error) değeridir. Bu değer aşağıdaki formül yardımılla hesaplanmıştır:

$$
R M S E=\sqrt{\frac{1}{n} \sum_{i=1}^{n}\left(y_{i}-\widehat{y}_{l}\right)^{2}}
$$

formülde $\hat{y}$ tahmin edilen fiyatı, $y$ ise gerçek fiyatı temsil etmektedir. Bu hata değeri ne kadar küçük çıkarsa, tahmin o kadar gerçeğe yakındır.

Çalışmada kullanılan bir diğer performans göstergesi yön tahmin oranıdır (hit rate). Söz konusu değer test süreci boyunca modelin tahmin ettiği yönler ile birlikte 
gerçekte var olan yönlerin karşılaştırılması ile aşağıdaki formül yardımıyla hesaplanmaktadır (Atsalakis vd., 2015)

$$
\text { doğru tahmin oranı }=\frac{h}{n}
$$

formülde, $h$ ifadesi test süreci boyunca doğru tahmin edilen fiyat artış ve azalışlarının toplam sayısını, $n$ ise test periodunun uzunluğunu ifade etmektedir. Bu çalışmada $n=60$ dir.

\subsection{Analiz Sonuçları}

Tablo 4'de seçilmiş hisse senetlerine ilişkin parametre ve optimize edilmiş değişken indeksleri yer almaktadır. Çalışmanın hacmini makul boyutta tutmak adına sadece 5 adet hisse senedine ilişkin optimize edilen parametreler ve değişken indeksleri tabloda listelenmiştir.

Tablo 4. Seçilmiş Senetlere İişkin Parametre ve Değişken İndeksleri

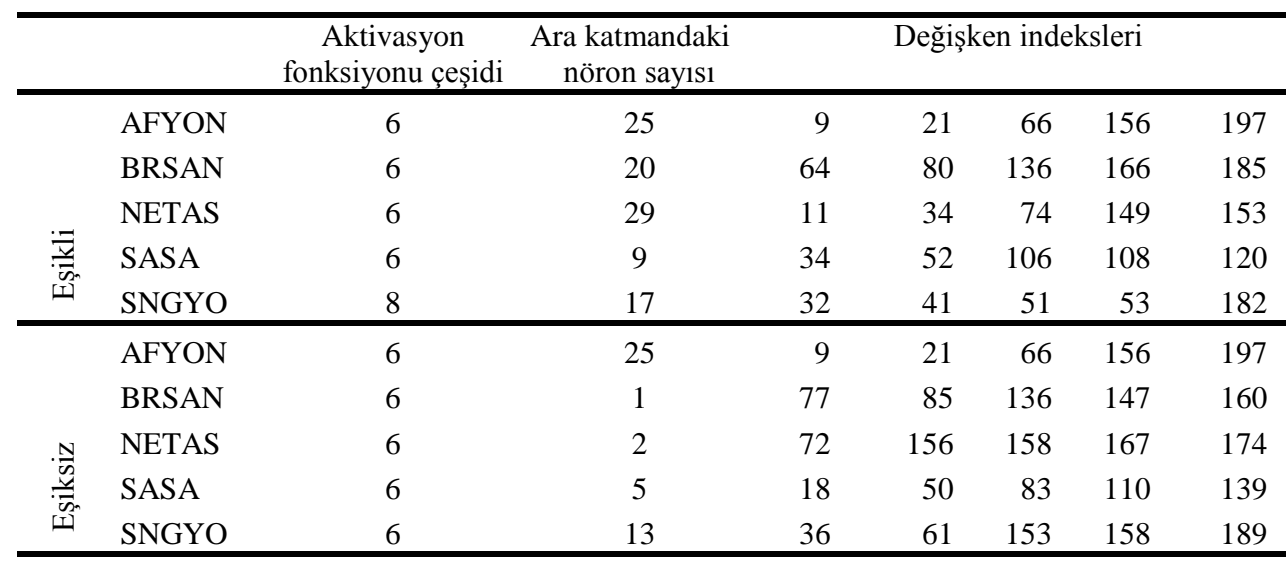

100 adet hisse senedinin tamamı için Tablo 4'deki gibi optimal parametreler belirlendikten sonra her model için belirlenen optimal parametre ve değişkenlerle birlikte eşikli ve eşiksiz modeller bir kez daha çalıştırılmıştır. Bu şekilde modellerin daha önce karşılaşmadığı test seti üzerindeki performansı ölçülmüştür. Eşikli ve eşiksiz modellerin doğru tahmin oranı performansları Tablo 5'de yer almaktadır. 
ÖZÇALICI $\mid$ Examining the Effect of Bias on Stock Price Prediction Performance

Tablo 5. Beş Adet Değişken Seçildiğinde Doğru Tahmin Oranları

\begin{tabular}{|c|c|c|c|c|c|c|c|c|}
\hline & Eşikli & Eşiksiz & & Eşikli & Eşiksiz & & Eşikli & Eşiksiz \\
\hline AEFES & 44.07 & 42.37 & GARAN & 57.63 & 57.63 & PRKME & 66.1 & 64.41 \\
\hline AFYON & 61.02 & 61.02 & GOLTS & 44.07 & 40.68 & SAFGY & 40.68 & 42.37 \\
\hline AKBNK & 59.32 & 57.63 & GOODY & 50.85 & 50.85 & SAHOL & 42.37 & 47.46 \\
\hline AKENR & 49.15 & 49.15 & GOZDE & 40.68 & 42.37 & SASA & 52.54 & 38.98 \\
\hline AKSA & 47.46 & 47.46 & GSRAY & 49.15 & 47.46 & SISE & 54.24 & 49.15 \\
\hline AKSEN & 62.71 & 59.32 & GSDHO & 44.07 & 42.37 & SKBNK & 35.59 & 35.59 \\
\hline ALARK & 52.54 & 50.85 & GUBRF & 52.54 & 50.85 & SNGYO & 37.29 & 32.2 \\
\hline ALBRK & 35.59 & 32.2 & HALKB & 59.32 & 54.24 & SODA & 50.85 & 50.85 \\
\hline ALGYO & 59.32 & 64.41 & HLGYO & 44.07 & 44.07 & TATGD & 59.32 & 59.32 \\
\hline ALKIM & 49.15 & 50.85 & HURGZ & 42.37 & 38.98 & TAVHL & 49.15 & 50.85 \\
\hline ANACM & 54.24 & 54.24 & IHLAS & 50.85 & 52.54 & TCELL & 44.07 & 45.76 \\
\hline ARCLK & 42.37 & 44.07 & IPEKE & 35.59 & 33.9 & TEKST & 35.59 & 27.12 \\
\hline ASELS & 55.93 & 55.93 & ISCTR & 45.76 & 45.76 & THYAO & 55.93 & 55.93 \\
\hline ASUZU & 54.24 & 54.24 & ISGYO & 47.46 & 47.46 & TKFEN & 49.15 & 45.76 \\
\hline AYGAZ & 40.68 & 47.46 & ITTFH & 32.2 & 40.68 & TKNSA & 40.68 & 42.37 \\
\hline BAGFS & 49.15 & 47.46 & IZMDC & 49.15 & 49.15 & TMSN & 49.15 & 35.59 \\
\hline BIMAS & 49.15 & 50.85 & KARSN & 38.98 & 38.98 & TOASO & 50.85 & 50.85 \\
\hline BIZIM & 40.68 & 37.29 & KARTN & 50.85 & 50.85 & TRCAS & 55.93 & 55.93 \\
\hline BJKAS & 55.93 & 59.32 & KCHOL & 49.15 & 55.93 & TRGYO & 44.07 & 38.98 \\
\hline BRISA & 50.85 & 54.24 & KIPA & 47.46 & 49.15 & TRKCM & 50.85 & 44.07 \\
\hline BRSAN & 55.93 & 57.63 & KONYA & 44.07 & 42.37 & TSKB & 45.76 & 35.59 \\
\hline CCOLA & 54.24 & 42.37 & KOZAA & 47.46 & 47.46 & TTKOM & 50.85 & 54.24 \\
\hline CIMSA & 50.85 & 49.15 & KOZAL & 59.32 & 59.32 & TTRAK & 55.93 & 59.32 \\
\hline CLEBI & 55.93 & 50.85 & KRDMD & 52.54 & 54.24 & TUPRS & 49.15 & 44.07 \\
\hline DOAS & 52.54 & 52.54 & LOGO & 27.12 & 30.51 & ULKER & 54.24 & 54.24 \\
\hline DOHOL & 45.76 & 45.76 & METRO & 50.85 & 52.54 & VAKBN & 57.63 & 57.63 \\
\hline ECILC & 49.15 & 49.15 & MGROS & 38.98 & 49.15 & VESBE & 47.46 & 52.54 \\
\hline ECZYT & 52.54 & 55.93 & MNDRS & 49.15 & 45.76 & VESTL & 44.07 & 44.07 \\
\hline EGEEN & 55.93 & 54.24 & NETAS & 44.07 & 40.68 & VKGYO & 55.93 & 50.85 \\
\hline EKGYO & 50.85 & 47.46 & NTHOL & 50.85 & 47.46 & YAZIC & 49.15 & 49.15 \\
\hline ENKAI & 47.46 & 47.46 & NTTUR & 40.68 & 33.9 & YKBNK & 54.24 & 54.24 \\
\hline EREGL & 54.24 & 54.24 & OTKAR & 55.93 & 54.24 & ZOREN & 50.85 & 37.29 \\
\hline FENER & 55.93 & 47.46 & PETKM & 40.68 & 40.68 & Ortalama & 49.14 & 48.14 \\
\hline FROTO & 49.15 & 49.15 & PGSUS & 55.93 & 50.85 & Max: & 67.80 & 64.41 \\
\hline
\end{tabular}

Hacettepe University Journal of Economics and Administrative Sciences 
Çalışmada eşik değerinin kullanıldığı modelde 100 adet hisse senedinde ortalama olarak \%49.14 oranında doğru bir tahmin gerçekleştirilirken, bu oran eşik (bias) değerinin kullanılmadığı modellerde \%48.14 olarak hesaplanmıştır (Tablo 5). Eşik değerinin kullanıldığı modellerde, eşik değerinin kullanılmadığı modellere göre daha yüksek isabetle tahmin gerçekleştirildiği görülmektedir. Ancak bu farklılığın istatistiksel olarak anlamlı bir farklılık arz edip etmediğinin test edilmesi gerekmektedir.

Borsa İstanbul'da faaliyet gösteren senetler içerisinde göreli olarak en iyi performans gösteren şirketler BIST100 endeksine dâhil edilmektedir. Dolayısıyla bu endekste bulunan senetler, Borsa İstanbul pay piyasasındaki senetlerin içerisinden rastgele değil belirli ölçütlere göre seçilmektedir. Başka bir ifade ile BIST100 Endeksinde listelenen senetler, ana kütle olan Borsa İstanbul'da işlem gören bütün senetleri en iyi şekilde temsil edecek bir örneklem oluşturmamaktadır. Bu durumda parametrik bir test kullanmak doğru olmayacaktır. Bununla birlikte eşikli bir YSA modelinde elde edilen sonuç eşiksiz modelde elde edilecek sonucu etkilemeyecektir. Bu nedenle örneklerin bağımsız olduğunu söylemek mümkündür. Buradan yola çıkmak suretiyle parametrik olmayan bağımsız örneklem Mann-Whitney $U$ testi testi kullanılmıştır.

Mann-Whitney U testinde sıfir hipotezi $\left(H_{0}\right.$ :) "eşikli modeller ile eşiksiz modellerde elde edilen doğru tahmin oranı değerleri aynı ana kütleden gelmektedir" şeklindedir. Önem derecesi $(\alpha=0.05)$ olarak kabul edildiğinde hesaplanan $\mathrm{p}$ değeri $(p=0.560, Z=0.9230)$, önem derecesinden büyük olduğu için sıfır hipotezini reddetmek için yeterli kanıt bulunmadığına kanaat getirilmiştir.

Tabloda ise 6'da ise beş adet değişken seçildiği durumda eşikli ve eşiksiz modellerin RMSE performans değerleri yer almaktadır.

Eşikli ve eşiksiz modellerde RMSE değerlerinin anlamlı farklılık sergileyip sergilemediğini belirlemek adına $\left(H_{0}\right)$ : "eşikli modeller ile eşiksiz modellerde elde edilen RMSE değerleri aynı ana kütleden gelmektedir" hipotezini test etmek için MannWhitney $\mathrm{U}$ testi kullanılmıştır. Bu durumda, $p$ değeri $(p=0.9639, Z=-0.0452)$ olarak hesaplanmıştır. Sonuçta, sıfır hipotezini reddetmek için yeterli kanıt bulunamamıştır.

Farklı sayılarda değişken kullanıldığında sonuçların ne olacağını incelemek adına 10,15 ve 20 adet değişken seçildiği durumlar için modeller tekrar çalıştırılmıştır. Tablo 7'de her bir durumda modellerin ortalama performans1 ve istatistiksel test sonuçlarına yer verilmiştir. Tabloya göre 10,15 ve 20 adet değişken seçildiği durumlarda da eşikli modeller ile eşiksiz modeller arasında anlamlı bir performans farklılı̆̆ gözlenememiştir. 
ÖZÇALICI | Examining the Effect of Bias on Stock Price Prediction Performance

Tablo 6. Eşikli ve Eşiksiz Modellerin RMSE Reğerleri $\left(\times 10^{-2}\right)$

\begin{tabular}{|c|c|c|c|c|c|c|c|c|}
\hline & Eşikli & Eşiksiz & & Eşikli & Eşiksiz & & Eşikli & Eşiksiz \\
\hline AEFES & 3.01 & 3.00 & GARAN & 2.86 & 2.88 & PRKME & 2.70 & 2.70 \\
\hline AFYON & 9.82 & 9.83 & GOLTS & 3.52 & 3.65 & SAFGY & 2.85 & 2.83 \\
\hline AKBNK & 3.22 & 3.26 & GOODY & 2.37 & 2.38 & SAHOL & 3.44 & 3.48 \\
\hline AKENR & 3.73 & 3.72 & GOZDE & 1.74 & 1.8 & SASA & 0.91 & 0.96 \\
\hline AKSA & 3.73 & 3.48 & GSRAY & 17.04 & 22.17 & SISE & 3.30 & 3.20 \\
\hline AKSEN & 4.20 & 4.32 & GSDHO & 3.93 & 4.00 & SKBNK & 3.95 & 3.96 \\
\hline ALARK & 3.37 & 3.30 & GUBRF & 2.60 & 2.67 & SNGYO & 5.93 & 4.64 \\
\hline ALBRK & 6.24 & 6.46 & HALKB & 3.63 & 3.89 & SODA & 1.88 & 1.87 \\
\hline ALGYO & 4.81 & 4.82 & HLGYO & 5.77 & 5.58 & TATGD & 2.76 & 2.77 \\
\hline ALKIM & 2.45 & 3.13 & HURGZ & 4.25 & 4.44 & TAVHL & 3.69 & 3.25 \\
\hline ANACM & 6.05 & 6.06 & IHLAS & 30.77 & 10.8 & TCELL & 3.21 & 3.40 \\
\hline ARCLK & 2.94 & 2.99 & IPEKE & 4.47 & 4.5 & TEKST & 1.27 & 0.90 \\
\hline ASELS & 3.26 & 3.24 & ISCTR & 2.96 & 2.96 & THYAO & 3.47 & 3.46 \\
\hline ASUZU & 4.13 & 4.09 & ISGYO & 5.17 & 5.2 & TKFEN & 2.86 & 2.86 \\
\hline AYGAZ & 4.21 & 4.18 & ITTFH & 2.39 & 2.45 & TKNSA & 4.54 & 2.84 \\
\hline BAGFS & 0.63 & 0.66 & IZMDC & 3.72 & 3.64 & TMSN & 4.34 & 5.54 \\
\hline BIMAS & 3.72 & 3.65 & KARSN & 4.11 & 2.93 & TOASO & 2.84 & 2.82 \\
\hline BIZIM & 2.49 & 2.46 & KARTN & 7.35 & 7.23 & TRCAS & 5.61 & 5.61 \\
\hline BJKAS & 3.64 & 3.69 & $\mathrm{KCHOL}$ & 1.96 & 1.97 & TRGYO & 4.39 & 4.52 \\
\hline BRISA & 2.53 & 2.53 & KIPA & 1.98 & 2.43 & TRKCM & 3.27 & 3.62 \\
\hline BRSAN & 3.08 & 3.00 & KONYA & 6.45 & 6.47 & TSKB & 7.22 & 7.26 \\
\hline CCOLA & 4.33 & 5.54 & KOZAA & 4.85 & 4.86 & TTKOM & 4.36 & 4.34 \\
\hline CIMSA & 3.70 & 3.70 & KOZAL & 3.23 & 3.22 & TTRAK & 2.63 & 2.62 \\
\hline CLEBI & 2.67 & 2.66 & KRDMD & 2.29 & 1.97 & TUPRS & 2.77 & 2.71 \\
\hline DOAS & 2.83 & 2.86 & LOGO & 1.87 & 1.88 & ULKER & 2.63 & 2.69 \\
\hline DOHOL & 5.91 & 5.91 & METRO & 2.70 & 3.83 & VAKBN & 3.12 & 3.09 \\
\hline ECILC & 5.63 & 5.64 & MGROS & 3.28 & 3.55 & VESBE & 2.02 & 2.25 \\
\hline ECZYT & 3.64 & 3.72 & MNDRS & 1.61 & 1.60 & VESTL & 1.95 & 1.94 \\
\hline EGEEN & 2.54 & 2.76 & NETAS & 3.48 & 3.28 & VKGYO & 0.56 & 0.88 \\
\hline EKGYO & 4.80 & 4.88 & NTHOL & 2.90 & 2.91 & YAZIC & 4.56 & 4.57 \\
\hline ENKAI & 2.16 & 2.17 & NTTUR & 3.05 & 3.45 & YKBNK & 2.85 & 2.76 \\
\hline EREGL & 3.31 & 3.26 & OTKAR & 2.71 & 2.42 & ZOREN & 1.42 & 1.44 \\
\hline FENER & 6.50 & 6.20 & PETKM & 3.39 & 3.39 & Ortalama & 3.92 & 3.78 \\
\hline FROTO & 2.61 & 2.63 & PGSUS & 2.27 & 2.11 & & & \\
\hline
\end{tabular}

Hacettepe University Journal of Economics and Administrative Sciences 
Tablo 7. Farkıı Sayıda Değişken Seçildiği Durumda Tahmin Sonuçları

\begin{tabular}{lccccc}
\hline Performans & Değ.Sayısı & $\begin{array}{c}\text { Eşikli Model } \\
\text { Ortalama }\end{array}$ & $\begin{array}{c}\text { Eşiksiz Model } \\
\text { Ortalama }\end{array}$ & P Değeri & Z Değeri \\
\hline RMSE & 10 & $4.29^{*}$ & $3.91^{*}$ & 0.6002 & 0.5241 \\
Hit Rate & 10 & 49.42 & 48.90 & 0.8226 & 0.2242 \\
Max Hit Rate & & 66.10 & 67.80 & & \\
RMSE & 15 & $3.76^{*}$ & $4.15^{*}$ & 0.8326 & -0.2114 \\
Hit Rate & 15 & 49.31 & 48.80 & 0.5172 & 0.6476 \\
Max Hit Rate & \multirow{6}{7}{67.80} & 64.41 & & \\
RMSE & 20 & $3.82^{*}$ & $3.78^{*}$ & 0.9231 & -0.0965 \\
Hit Rate & 20 & 49.54 & 49.34 & 0.8974 & -0.1289 \\
Max Hit Rate & 67.80 & 64.41 & & \\
\hline \multicolumn{7}{c}{$*\left(\times 10^{-2}\right)$} \\
\hline
\end{tabular}

Eşikli ve eşiksiz modellerin çalışma sürelerini ölçmek için modellerin çalışmaya başladıkları süre ve çalışmanın sona erdiği süreler kaydedilmiştir. 100 adet hisse senedi için toplam çalışma süreleri dakika cinsinden Tablo 8 'de sunulmuştur. Tablodaki sonuçlara göre eşik değerlerinin yer almadığı modeller, eşik değerlerinin yer aldığı modellere göre daha hızlı sonuç vermektedir. Eşik değerlerine izin verilen modellerde, eşik değerleri de eğitim algoritması tarafindan optimize edilmesi gereken bir unsur olarak göz önünde bulundurulmaktadır. Bu nedenle eşik değerlerinin yer aldığı modellerin eğitimi daha uzun sürmektedir.

Tablo 8. Eşikli ve Eşiksiz Model Toplam Çalışma Süreleri (dk)

\begin{tabular}{lcc}
\hline Seçilen değişken sayıs1 & Eşikli Model & Eşiksiz Model \\
\hline 5 adet değişken & 76.72 & 57.62 \\
10 adet değişken & 75.88 & 74.58 \\
15 adet değişken & 105.78 & 97.82 \\
20 adet değişken & 117.27 & 118.43 \\
\hline
\end{tabular}

Eşikli değerler ile eşiksiz değerlerin tahmin ettiği fiyatlar ile gerçek fiyatlar grafiklerde gösterilmiştir (Şekil 2). Her bir hisse senedi için ve her bir modelin tahmin ettiği fiyatları grafik üzerinde göstermek çalışmanın hacmini gereğinden fazla arttıracaktır. Bu nedenle sadece EGEEN isimli hisse senedine ilişkin grafikler çizilmiştir. Grafiklerde hem eşik değerlerinin yer aldığı hem de eşik değerlerinin yer almadığı modellerin gerçek fiyatlara yakın sonuçlar ortaya çıkardığı görülmektedir. 
Şekil 2. EGEEN İsimli Hisse Senedi İçin Tahmin Edilen Fiyatlar
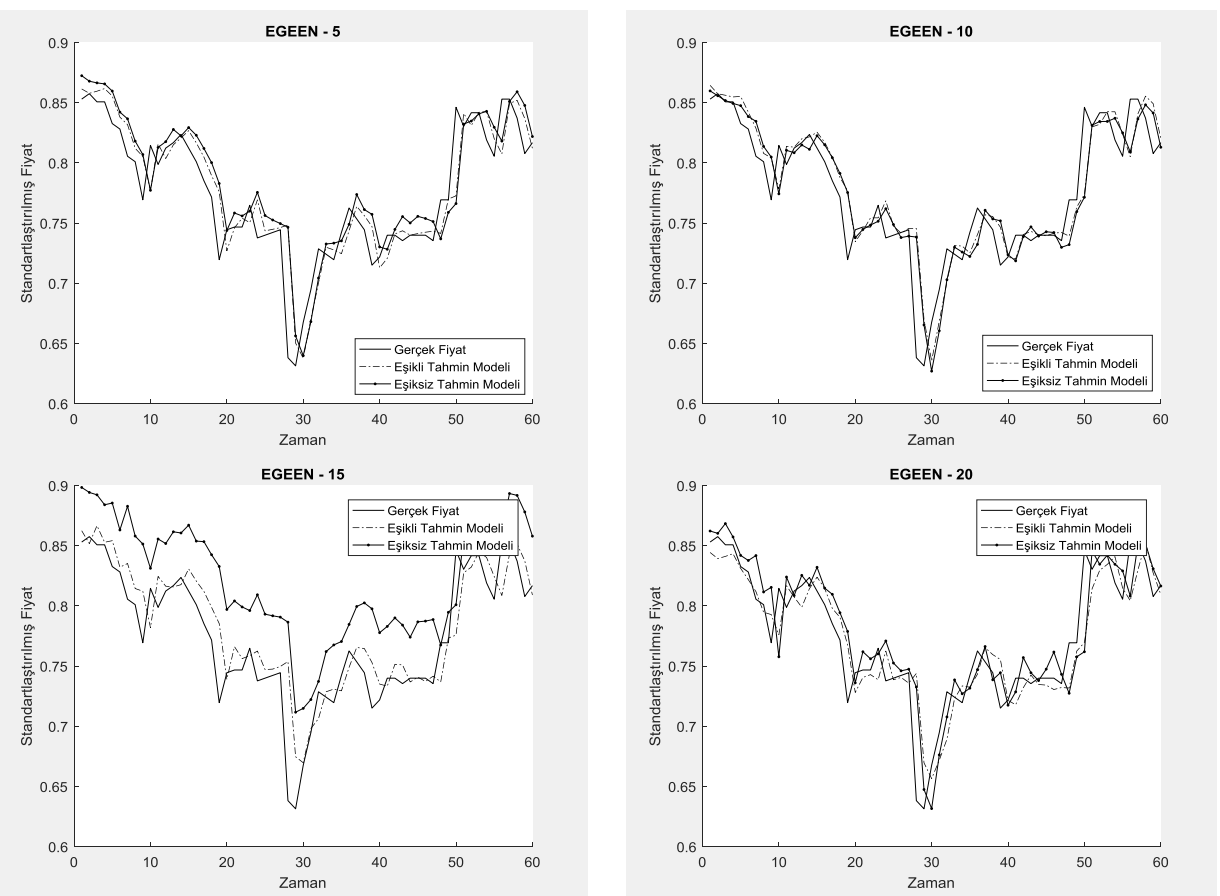

\section{SONUÇ VE TARTIŞMA}

Hisse senedi fiyatlarının doğru bir şekilde tahmin edilmesi yatırımcılar için oldukça önemlidir. Fiyatların doğru bir şekilde tahmin edilmesi, yatırım kaynaklarının doğru yönlendirilmesini sağlayacaktır. $\mathrm{Bu}$ nedenle farklı bilim dallarından araştırmacılar, hisse senedi fiyat tahmin oranını arttıracak modeller üzerinde çalışmaktadır.

Hisse senedi fiyat tahmin çalışmalarında kullanılan yöntemlerden biri de yapay sinir ağlarıdır. Eşik değerinin hisse senedi fiyat tahmini konusundaki performansının incelendiği bir çalışmaya literatürde rastlanmamıştır. Bu çalışmada, eşik (bias) değerinin tahmin performansı üzerindeki etkisi incelenmiştir. Bu amaçla BIST100 Endeksinde listelenen hisse senetlerine ait tarihi fiyat ve işlem hacmi bilgilerini kullanmak suretiyle, tahmin modelleri oluşturulmuştur. İki temel model oluşturulmuştur. İlk modellerde eşik değerleri bağlantılarına izin verilirken, ikinci modellerde eşik değeri kullanılmamıştır. Oluşturulan modellerde kullanıcının karar vermesi gereken parametrelere harmoni arama algoritması ile karar verilmiştir. Performans ölçüsü olarak RMSE ve tahmin çalışmalarında sıklıkla kullanılan doğru tahmin oranı değerleri kullanılmıştır. Çalışma sonucunda ortaya çıkan verilerin anlamlı farklılık arz edip etmediğini test etmek için, bağımsız örneklem Mann Whitney U testi 
uygulanmıştır. Sonuç olarak eşik değerlerinin kullanıldığı modeller ile kullanılmadığı modeller arasındaki istatistiksel olarak anlamlı performans farklılı̆ı tespit edilememiştir. Sonuçlar göz önüne alındığında eşik değerlerinin sıfira eşitlenmesi, hisse senedi fiyat tahmin performansı üzerinde belirgin bir artış ya da azalışa neden olmamıştır. Bunun yanı sıra eşik değerlerinin yer aldığı modeller ve yer almadığı modellerin eğitim süreleri karşılaş̧ırıllmış ve eşik değerlerinin yer almadığı modellerin eğitiminin daha kısa sürdüğü belirlenmiştir.

Çalışmanın dikkat çeken sonuçlarından biri de seçilen aktivasyon fonksiyonu ile ilgilidir. Harmoni arama algoritması tarafindan YSA modellerinde ara katmanda yer alması gereken aktivasyon fonksiyonu modellerin çoğunda saf doğrusal aktivasyon fonksiyonu optimal olarak belirlenmiştir. 800 adet modelin hiçbirinde hard limit aktivasyon fonksiyonu optimal olarak belirlenmemiştir. Bu durum modellerin olması gerektiği gibi çalıştığının bir göstergesidir.

Çalışmanın bazı kısıtları mevcuttur. İlk olarak teknik göstergeler kullanılmıştır. İlerleyen çalışmalarda eşiksiz YSA modellerinin uzun dönemli performansları temel göstergeler kullanmak suretiyle incelenebilir. Dolayısıyla firmaların mali oranları, diğer ülkelerin borsaları, döviz kurları gibi temel göstergeler kullanmak suretiyle eşik değerinin etkisi daha detaylı bir şekilde incelenebilir. Buna ek olarak, eşik değerinin farklı borsalardaki hisse senetlerinin tahmin performansı üzerindeki etkisi incelenebilir.

\section{KAYNAKÇA}

Achelis, S.B. (2001), Technical Analysis From A to Z, New York: McGrawHill.

Adhikari, R., R.K. Agrawal (2014), "A Combination of Artificial Neural Network and Random Walk Models for Financial Time Series Forecasting", Neural Computing and Applications, 24(6), 1441-1449.

Asadi, S., E. Hadavandi, F. Mehmanpazir, M.M. Nakhostin (2012), "Hybridization of Evolutionary Levenberg-Marquardt Neural Networks and Data Pre-Processing for Stock Market Prediction", Knowledge-Based Systems, 35, 245-258.

Atsalakis, G.S., E.E. Protopapadakis, K.P. Valavanis (2015), "Stock Trend Forecasting in Turbulent Market Periods Using Neuro-Fuzzy Systems", Operational Research, 16(2), 245-269.

Atsalakis, G.S., K.P. Valavanis (2009a), "Forecasting Stock Market Short-Term Trends Using a Neuro-Fuzzy Based Methodology", Expert Systems with Applications, 36(7), 1069610707.

Atsalakis, G.S., K.P. Valavanis (2009b), "Surveying Stock Market Forecasting Techniques-Part II: Soft Computing Methods", Expert Systems with Applications, 36(3 PART 2), 59325941.

Aygören, H., H. Sarıtaş, T. Moralı (2012), "İMKB 100 Endeksinin Yapay Sinir Ağları ve Newton Nümerik Arama Modelleri ile Tahmini", Uluslararası Alanya İşletme Fakültesi Dergisi, 4(1), 73-88. 
ÖZÇALICI | Examining the Effect of Bias on Stock Price Prediction Performance

Dai, W., Y.E. Shao, C.J. Lu (2012), "Incorporating Feature Selection Method into Support Vector Regression for Stock Index Forecasting", Neural Computing and Applications, 1551-1561.

Fama, E.F. (1965), "The Behavior of Stock-Market Prices", Journal of Business, 38(1), 34-105.

Hagan, M.T., H.B. Demuth, M.H. Beale (1996), Neural network design. Boston Massachusetts $P W S$ (Vol. 2), Retrieved from http://ecee.colorado.edu/academics/schedules/ECEN5120.pdf

Hsu, C.M. (2013), "A Hybrid Procedure with Feature Selection for Resolving Stock/Futures Price Forecasting Problems", Neural Computing and Applications, 22(3-4), 651-671.

Kara, Y., M.A. Boyacioglu, Ö.K. Baykan (2011), "Predicting Direction of Stock Price Index Movement Using Artificial Neural Networks and Support Vector Machines: The Sample of the Istanbul Stock Exchange", Expert Systems with Applications, 38(5), 5311-5319.

Kaufman, P.C. (1998), Trading Systems and Methods (3rd Edition), Canada: Wiley \& Sons.

Mahmud, M.S., P. Meesad (2015), "An Innovative Recurrent Error-Based Neuro-Fuzzy System with Momentum for Stock Price Prediction", Soft Computing, 20(10), 4173-4191.

Özçalıcı, M. (2015), Hisse Senedi Fiyat Tahminlerinde Bilgi İşlemsel Zeka Yöntemleri: Uzman Bir Sistem Aracılığıyla BIST Uygulaması, Kahramanmaraş: Kahramanmaraş Sütçü İmam Üniversitesi, Doktora Tezi.

Özdemir, Ö. (2015), "An Improved Method for Forecasting Borsa Istanbul 100 Index by Neural Network Based Fuzzy Time Series and Particle Swarm Optimization", In 16th International Symposium on Econometrics, Operations Research and Statistics, Edirne.

Palit, A.K., D. Popovic (2005), Computational Intelligence in Time Series Forecasing: Theory and Engineering Applications, London: Springer-Verlag.

Sarıkaya, G. (2014), "Forecasting Bist National-100 Index by Using Artificial Neural Network and Regression Models", In 15th International Symposium on Econometrics, Operations Research and Statistics, 155-166, Isparta.

Wu, Y., R.M. Rangayyan (2007), "An Algorithm for Evaluating the Performance of Adaptive Filters for the Removal of Artifacts in ECG Signals", In 2007 Canadian Conference on Electrical and Computer Engineering, 864-867, IEEE.

Yakut, E., B. Elmas, S. Yavuz (2014), "Yapay Sinir Ağları ve Destek Vektör Makineleri Yöntemleriyle Borsa Endeksi Tahmini", Süleyman Demirel Üniversitesi, İktisadi ve Ídari Bilimler Fakültesi Dergisi, 19(1), 139-157.

Yang, J., W. Wu (2007), "Is Bias Dispensable for Fuzzy Neural Networks?", Fuzzy Sets and Systems, 158(24), 2757-2762.

Yang, X.S. (2009), "Harmony Search as a Metaheuristic Algorithm", Studies in Computational Intelligence, 191, 1-14.

Yu, L., S. Wang, K.K. Lai (2005), "Mining Stock Market Tendency Using GA-Based Support Vector Machines", Lecture Notes in Computer Science (including Subseries Lecture Notes in Artificial Intelligence and Lecture Notes in Bioinformatics), 3828 LNCS, 336345.

Zhai, F., Q. Wen, Z. Yang, Y. Song (2010), "Hybrid Forecasting Model Research on Stock Data Mining", New Trends in Information Science and Service Science (NISS), 2010 4th International Conference on, Gyeongju, 630-633. 